\title{
RADIOCARBON STUDIES OF PEAT BOGS: AN INVESTIGATION OF SOUTH KAMCHATKA VOLCANOES AND UPPER VOLGA ARCHEOLOGICAL SITES
}

\author{
N E Zaretskaia ${ }^{1} \cdot$ V V Ponomareva ${ }^{2}$ L D Sulerzhitsky ${ }^{1} \cdot$ M G Zhilin ${ }^{3}$ \\ ABSTRACT. We have undertaken extensive programs of natural radiocarbon measurement to date the evidence for various \\ events buried in peat bogs. Two case studies are described here: 1) the chronological reconstruction of South Kamchatka vol- \\ canic eruptions and, 2) investigation of multi-layered archeological sites in the Upper Volga River Basin. Studies of sample \\ composition and peat taphonomy allowed us to determine the source of ${ }^{14} \mathrm{C}$ age deviations and to reconstruct the environmen- \\ tal history of organic matter accumulation. Data sets, obtained from different types of peat bog and containing traces of these \\ Holocene events, are discussed.
}

\section{INTRODUCTION}

Radiocarbon dating is now used worldwide to provide age estimates for various Late PleistoceneHolocene events that relate to a broad range of natural science topics. Included here are volcanisms, archaeology, and human evolution, the history of mega-fauna, environmental changes etc. In practice, various types of organic detritus are monitored to provide either direct estimations of ${ }^{14} \mathrm{C}$ age of sedimentary deposits or the indirect (implied) age of specific events or artifacts recorded within the deposit. Peat is an ideal dating medium due to its high organic content, the relatively rapid accumulation of peat deposits, and the excellent preservation environment it provides for event traces such as volcanic ash layers, archeological artifacts, tsunami deposits, etc. The aim of the research described in this paper was the detailed ${ }^{14} \mathrm{C}$ dating of peat bogs undertaken to enable "high-resolution" age evaluation of the evidence for specific events recorded in the buried profiles. We have chosen Holocene peat bogs as the focus of our studies, because they started to grow almost at the same time in different places i.e., following on the last glacial to post-glacial transition. Furthermore, in many different geographical areas clear evidence for various local and/or regional events has been imprinted during ongoing peat growth. Thus, it is appropriate to regard peat bogs as natural "databases" that are potentially rich in varied and detailed information about those paleoenvironmental conditions and changes that have occurred during the last 12,000-10,000 yr. However, it must be appreciated that all peat bogs are "living-systems." As a consequence, there is an inherent degree of heterogeneity in the organic matrix due to the different ages of the plant components that have contributed to peat formation. This is liable to vary depending on the particular bog environment. In any dating exercise it is essential, therefore, to consider the origin of each sample and any peculiarities of peat accumulation at the host bog deposit to ensure best confidence in the precision and reliability of each age measurement.

Two case studies, each involving detailed ${ }^{14} \mathrm{C}$ dating from different bog types, are discussed. The dates were measured during the period of 1997 through 1999.

1. The first case involved a program of detailed dating of the evidence for volcanic and associated events imprinted in the South Kamchatka peat bogs. Various volcanic eruptions and associated mudflows (lahars) occurred frequently on the Kamchatka peninsula during Holocene time. Volcanic ash layers with thickness ranging from a few millimeters to tens of centimeters, were deposited over the peat bogs resulting in an extensive archive of information about the pyro-

\footnotetext{
${ }^{1}$ Geological institute of RAS, Pyzhevsky per. 7, Moscow, 109017, Russia. Email: zaretsk@geo.tv-sign.ru.

${ }^{2}$ Institute of Volcanic Geology and Geochemistry, Far East Division of RAS, Boulevard Piipa 9, Petropavlovsk-Kamchatsky, 683006, Russia

${ }^{3}$ Institute of Archeology of RAS, Dm. Ulianov St 19, Moscow, 117036, Russia
}

(C) 2001 by the Arizona Board of Regents on behalf of the University of Arizona

RAdiocarbon, Vol 43, Nr 2B, 2001, p 571-580

Proceedings of the 17 th International ${ }^{14} \mathrm{C}$ Conference, edited by I Carmi and E Boaretto 
clastic successions and general environmental history of the Kamchatka region. Our earlier attempt at detailed ${ }^{14} \mathrm{C}$ dating of peat pyroclastic section was undertaken at Chernyi Yar section in the valley of the Kamchatka River (Pevzner et al. 1998). The main goal of our study was to obtain reliable age estimates for several strong and moderate volcanic eruptions and associated events that had occurred throughout the South Kamchatka region. We realized that this objective required an inherent investigation of the suitability of different types of peat derived organic carbon for accurate age assessment. In particular, there was a need to identify and avoid possible sources of age discrepancy within those natural peat sections that had recorded evidence of volcanic ash fall.

2. The second case was based on detailed ${ }^{14} \mathrm{C}$ dating applied at two multi-layered Mesolithic to Neolithic peat sites located within the Upper Volga River Basin of Central Russia. Extensive research of the Middle Russia peat bogs (including Ivanovskoe discussed here), were conducted in the 1960s and 1970s (Khotinsky 1977), but the work focused mostly on peat stratigraphy and pollen analysis. However, prior to our study very few ${ }^{14} \mathrm{C}$ dates were available from surveyed sites (Sulerzhitsky et al. 1998; Zhilin 1999). Our main goal was to determine the best ${ }^{14} \mathrm{C}$ dating precision that could be ascribed to specific archaeological layers buried in peat bogs and thereby improve their value in any reconstruction of the history of settlement. We also considered the need to quantify the degree of synchronism that could be ascribed to individual dates measured from an archaeologically defined peat layer and/or its enclosed artifacts. This in context of a need to resolve the possibility of different archaeological cultures co-existing within the same area.

\section{STUDY AREAS}

Two key areas were chosen for our research:

1. Sampling for reconstruction of the Holocene volcanic history of South Kamchatka centered on the Kurile Lake caldera area. This region contains the five southernmost active volcanoes on the peninsula: Zheltovsky (1957 m), Iliinsky (1577 m), Dikiy Greben' (1079 m), Koshelev $(1853 \mathrm{~m})$, and Kambalny $(2161 \mathrm{~m})$. The catastrophic eruption that formed the caldera occurred at around $7700 \mathrm{BP}$ and was accompanied by the emission of voluminous pyroclastic deposits that carpeted the lowlands of South Kamchatka (Braitseva et al. 1995). The Iliinsky and Dikiy Greben' volcanoes formed subsequent to this initial eruption (Braitseva et al. 1995; Ponomareva et al. 1995). The peat bogs available for the present investigation started forming in depressions in the impermeable deposits laid down as debris avalanches that resulted from a strong eruption of Kambalny at about 6000 BP (Ponomareva et al. 1995). The onset of peat accumulation is dated at $5550 \pm 120 \mathrm{BP}$ (GIN-9188).

2. Our archaeological investigations featured two multi-layered sites within the Upper Volga River basin northeast of Moscow, Ivanovskoe-7 and Stanovoe-4, which are 140 and $240 \mathrm{~km}$ from the city, respectively. Both sites are located within a sub-latitudinal "belt" of mezolithicneolithic peat sites. During the past ten years these sites have been excavated by Dr Zhilin (1998). A few ${ }^{14} \mathrm{C}$ dates were available (Sulerzhitsky et al. 1998), but for the most part these are derived from wood fragments. The peat profile at Ivanovskoe-7 contained evidence of five discrete cultural layers (three mesolithic and two neolithic). However, the record of later occupation had been destroyed by the installation of local drainage systems (Zhilin 1998). Stanovoe4 afforded a well-preserved record of four cultural layers: three mesolithic and one neolithic (Zhilin 1999). 


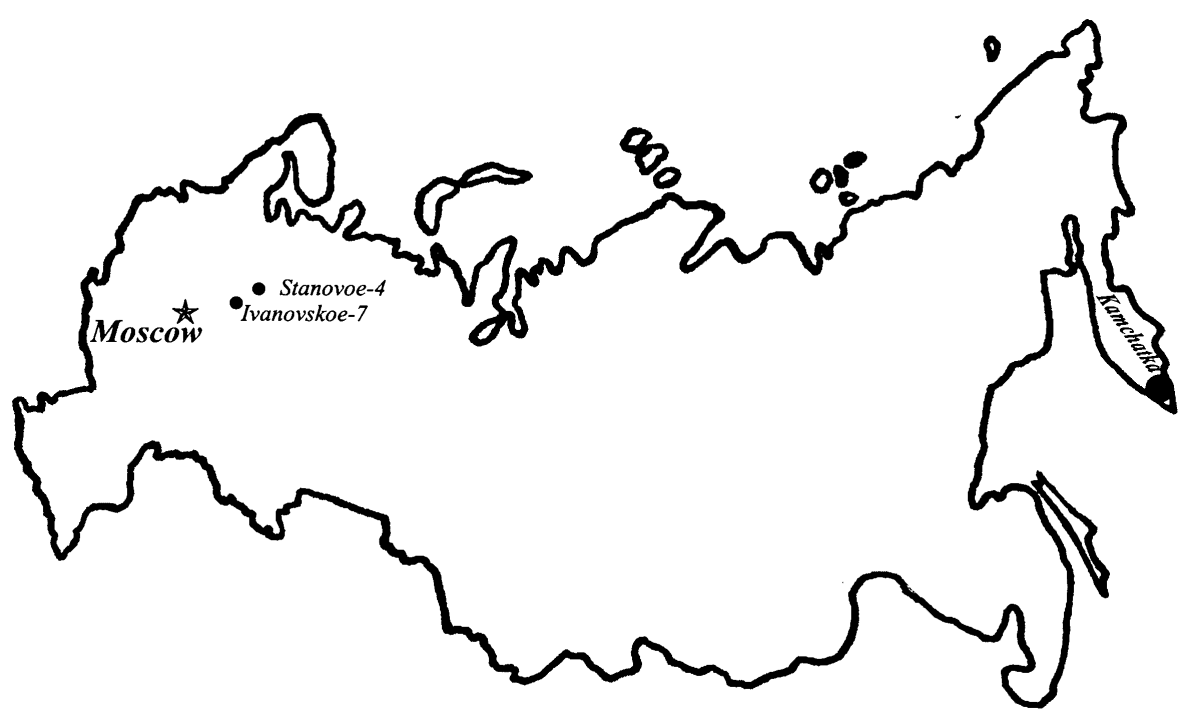

Figure 1 Key areas on the map of Russia

\section{METHODS}

\section{Field Research}

Samples for ${ }^{14} \mathrm{C}$ dating were collected during fieldwork expeditions to South Kamchatka in 1996/97 and the Upper Volga River basin sites in 1997/98.

Six peat sections ranging from the depth of 1-2.5 m were sampled to establish a chronology for Holocene volcanic activity in South Kamchatka. Individual sections recorded between 8 and 20 ash layers inter-bedded in the peat profile. The sections were tephra-chronologically correlated and the ash sources identified. Much of the South Kamchatka peat has a coarse composition but is well-preserved and in several instances the fragments of specific peat forming plants can be identified.

Each peat profile was subjected to fine resolution sampling. A thin $(1.0-1.5 \mathrm{~cm})$ slice of peat was recovered from the upper and lower contact surfaces of each ash and lahar horizon and from the base of the peat accumulation. Due to the relatively rapid rates of peat growth the actual timing of an eruption event is well resolved by the underlying and overlying ${ }^{14} \mathrm{C}$ dates. Since the volcanic ash (tephra) records an essentially instantaneous event then each layer represents a regional isochrone within the depositional succession. Therefore, direct inter-comparison of the ${ }^{14} \mathrm{C}$ dates measured for the same ash layer at different sites in South Kamchatka afforded us a criterion for examination of the general reliability and precision of ${ }^{14} \mathrm{C}$ dates obtained from peat bog samples.

We made a very detailed ${ }^{14} \mathrm{C}$ sampling from the two multi-layered peat sites. The evidence for significant archaeological events was exposed by excavation of 1-2 $\mathrm{m}$ deep vertical sections through the peat/gyttja deposits. Three sections were prepared at Ivanovskoe-7 and two at Stanovoe-4. Between 10 and 15 samples were recovered from each section. Peat/gyttja samples were taken to represent the top and bottom of each identified cultural and/or stratigraphic horizon. The thickness of each sample did not exceed $1.5 \mathrm{~cm}$. Many other individual samples of wood and bone fragments we collected to 1) supplement the peat/gyttja chronology, and 2) represent apparently contemporaneous archaeological levels at different inter and intra site locations. This latter strategy of replicate 
sampling was intended to determine the level of agreement that could be obtained by independent dating across the same archaeological and/or stratigraphic level.

Peat at the two Upper Volga sites is typically rather dense and homogeneous in composition due to a relatively rapid rate of biological degradation. However, other organic remnants such as wood fragments, artifacts, and even bone tend to be well-preserved. All samples were collected into plastic bags and then transported to the Geological Institute in Moscow.

\section{${ }^{14} \mathrm{C}$ Dating}

All samples were pretreated and their ages measured in the Radiocarbon division of the Laboratory for Isotope Geochemistry and Geochronology which is a component of the Geological Institute of Russian Academy of Sciences (GIN). In most instances, the samples were pretreated and dated very soon after their field collection.

Peat and gyttja samples were crushed and then washed through a $2 \mathrm{~mm}$ sieve with distilled water to remove sand or volcanic ash from the peat. The bulk residue was digested in hot $5 \% \mathrm{HCl}$ and then rinsed with distilled water. For the next pretreatment stage each sample was sub-divided equally and then extracted with $\mathrm{NaOH}$ using two different procedures designed to separate and recover organic matter representing different rates of preservation. A cold alkaline extraction ( $20 \mathrm{~min}$ in $2 \% \mathrm{NaOH}$ ) and a hot alkaline extraction (an additional $20 \mathrm{~min}$ of boiling in $2 \% \mathrm{NaOH}$ ). In case of samples that showed a high degree of identifiable plant remnants preservation (which occurred only in the case of some Kamchatka peats) dating of the "alkali insoluble" remnants was restricted to the fraction (mainly stem and root fragments) recovered from the "cold extraction". Following centrifugation, the humic acid fraction was precipitated from each $\mathrm{NaOH}$ extract by the addition of $\mathrm{HCl}$. The precipitates were recovered by centrifugation, dried, washed with cold distilled water, and finally redried. The alkali insoluble plant remnants were washed with hot $5 \% \mathrm{HCl}$ solution, rinsed with cold distilled water, and dried. Both the humic acid fraction and the alkali/acid insoluble residues were dated to obtain at least two ${ }^{14} \mathrm{C}$ age measurements from each bulk sample.

Wood and bone samples were pretreated and dated using routine procedures that are used at GIN. Wood samples were subjected to the standard A-A-A pretreatment; the sample was first cleaned by standing in hot $5 \% \mathrm{HCl}$, washed with distilled water, and then boiled for $20 \mathrm{~min}$ in $2 \% \mathrm{NaOH}$ solution. The alkali insoluble wood fragments were then digested in hot $5 \% \mathrm{HCl}$ and finally washed with distilled water. In the case of bone samples, the collagen fraction was extracted and recovered using the procedures detailed by Sulerzhitsky (1997); Sulerzhitsky and Romanenko (1999). In essence, initial cleaning was achieved by prolonged exposure of samples to dilute $\mathrm{HCl}$ soluble fraction in a refrigerator. The resultant demineralized collagen was diluted, purified by centifugation, and finally evaporated to dryness.

All pretreated samples (alkaline extractions, wood, and collagen) were charred prior to benzene synthesis, which was achieved using the procedure described by Braitseva et al. (1993). Natural ${ }^{14} \mathrm{C}$ activities were measured by liquid scintillation counting of the prepared benzene samples. We did not measure ${ }^{13} \mathrm{C}$ enrichment values, and consequently the reported age values are not normalized to compensate for isotopic fractionation effects.

\section{Paleobotanical Analysis}

Peat is a heterogeneous and heterochronous mixture of plant debris that has undergone various degrees of biological degradation, in which case the identifiable remains of specific plants is the main and most important characteristic (feature). We performed plant remnant analysis of all dated 
peat samples from South Kamchatka to ascertain the peculiarities of peat accumulation and vegetation taphonomy in those bogs. These analyses were undertaken by Olga N Uspenskaia at the Russian Agricultural Academy. She confirmed that the South Kamchatka peats are composed mostly of various Carex species and mosses; the Carex remains are mainly roots whereas those of mosses are predominantly stem fragments. Each plant species was examined in the Herbarium of the Institute of Botany in St. Petersburg and this exercise provided a detailed history of the plant taphonomy and vegetation changes that characterized each peat bog.

\section{RESULTS AND DISCUSSION}

The radiometric time span between the two contemporaneous humic extractions ("hot" and "cold"), or between the "cold alkali extract" and cellulose fractions, is a direct measure of the extent of apparent age variation that can be encountered within a physically defined layer of peat. We used this "two sub-sample" approach in dating both the Kamchatka and Upper Volga peats.

By dating two component fractions from peat immediately under and immediately above a particular ash layer, we have been able to reduce the time interval within which we can place the age of the volcanic eruption. We set these time limits to correspond with the oldest valid date above the ash and the youngest under it. This reasoning was employed also to sharpen the age estimates for cultural layers and/or the timing of environmental change events evidenced in the peat profiles.

Furthermore, the comprehensive pool of carefully defined ${ }^{14} \mathrm{C}$ age measurements obtained from "key-area" peat bogs allowed us to expand significantly our appreciation of peat as a medium for objective ${ }^{14} \mathrm{C}$ dating. We were also able to produce a detailed reconstruction of the histories of various Holocene events.

\section{Case Study 1}

We recorded a total of about $200{ }^{14} \mathrm{C}$ age measurements based on samples recovered from six peat sections within the South Kamchatka study area. Each section showed a general trend of increasing age with depth but there were some evident anomalies that were related to variations in the composition of the bulk peat.

About 20 ash layers were dated together with several lahars from the Kambalny volcano. In the case of the latter features ( 3 in the upper and 2 in the lower profile sections) the overlying and underlying peat dates were compared directly with those stratigraphically comparable values obtained by dating the remnants of wood that had been captured by the lahar flows. The six peat-pyroclastic sections were also cross-correlated on the basis of their individually identifiable tephra layers. Thus, the ashfall sequences could be used to test, and where necessary, constrain the integrity of the conventional ${ }^{14} \mathrm{C}$ age measurements. This independent tephra-chronological framework together with the results of the plant macro-fossil analyses provided a secure basis for our evaluation of the presence and range of ${ }^{14} \mathrm{C}$ age deviations that can occur as a consequence of those variations in plant sources that are characteristic of the Kamchatka peat bogs. The significantly divergent range of ${ }^{14} \mathrm{C}$ ages that can be obtained from the different components of bulk peat in the Kamchatka region is exemplified in Figure 2a. In many instances such variations can be ascribed to growth characteristics of the particular plants. For example, some species of Carex, such as Carex cryptocarpa and C. vesicata, spread their living roots down through the underlying peat and this "younger" organic material is thus injected directly into older stratigraphic levels i.e., vertical taphonomy. Even the presence of an ash layer does not necessarily prevent the downward penetration of such roots. For this reason the dates obtained from Carex derived material are sometimes significantly younger than those measured 


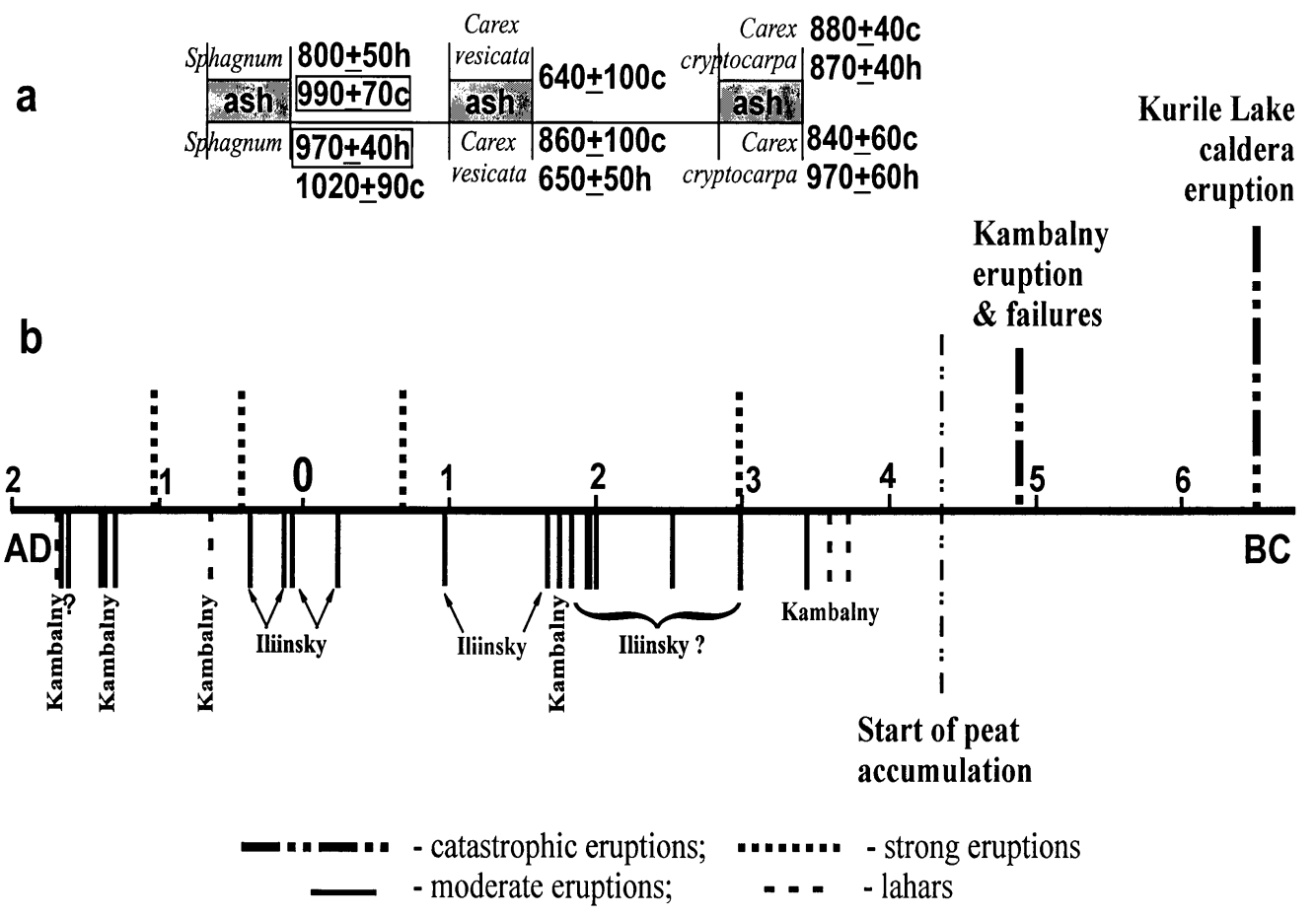

Figure 2 a) Radiocarbon dates for the same ash from different sections: valid dates are in black rectangles; dominant plant species are in italics; b) calendar of events, imprinted in the peat bogs of South Kamchatka.

from the remains of other plant precursors within the same stratigraphic level (Figure 2a). Therefore, we paid particular attention to questioning the chronological integrity of dates obtained from peats that contained the organic detritus of these Carex species before using them for estimation of the age of volcanic events. The preferred dates were obtained from peat composed from rootless mosses (Sphagnum and Bryales) or other Carex species, such as Carex lasiocarpa, that form very well separated layers of peat i.e. horizontal taphonomy. Criteria for selection of the most valid dates, e.g. those listed within black rectangles in Figure 2a, were based on the conventions described above.

After we had identified and selected a suite of the most valid measurements these were used to determine the average conventional ${ }^{14} \mathrm{C}$ age of each volcanic event that had been imprinted into the South Kamchatka bogs. The chronological data set was then calibrated to equate with calendar time using Calib 4.2 (Stuiver et al. 1998). The resulting time-stratigraphic scale for eruptive events associated with the South Kamchatka volcanoes is described in Figure 2b. It seems unlikely that this reconstruction, which is based on the combined record from only six locations, will have recorded and recognized all of the eruptions that have occurred in South Kamchatka during the Holocene. However, it does provide an invaluable framework for the future correlation of other soil-pyroclastic sections not yet dated, and with the eventual promise of a detailed and comprehensive record of postglacial volcanic events across the entire region.

In this context, it is appropriate to recognize that ash fall events can often have a strong influence on the composition of vegetation cover on the developing peat bog; sometimes causing a complete change. Ongoing reconstruction of this record of abrupt vegetation changes will provide new and 
complimentary information concerning those relationships between climate and volcanic eruptions that have influenced post-glacial swamp development on the Kamchatka peninsula.

\section{Case Study 2}

We measured about $50{ }^{14} \mathrm{C}$ dates from each of the two archaeological sites. For the most part these age data were derived from peat/gyttja samples with the remainder based on artifacts and other types of organic detritus. Our "three dimensional" approach to on-site sampling allowed us to 1) record ${ }^{14} \mathrm{C}$ age data from the various points and levels as defined for occupational reconstruction at each multi-layer settlement, and 2) assess the suitability of the several sample types for objective dating at these particular sites.

In general, the dates obtained from peat/gyttja samples within the same stratigraphic level show good concordance. Notable exceptions occur (see Figure 3) at a) section 2 (S2) at Stanovoe-4 and due to its location and the consequent re-deposition of peat in a paleo-bed of the Lahost River, and b) the base of section 2 (S2) at Ivanovskoe-7, and due to the effects of shoreline erosion and the redeposition of organic detritus.

There are no obvious age/depth inversions in these sections, which supports the contention that the organic sediments accumulated progressively and in-situ. In most instances the ages derived from naturally implanted wood fragments tend to be much younger than their surrounding deposits and therefore, must be regarded as having little or no value as indicators of archaeological significance. This pattern of discrepancy between the ages of raw (non-worked) wood fragments and the surrounding peat/gyttja deposit is characteristic of each settlement. We suspect that these wood fragments are remnants from bog trees that fell down and sank to older stratigraphic levels in the peat/gyttja host deposit. In contrast, the dates recorded from wooden artifacts (fish-traps, stakes, boards etc.) and from animal bones and bone artifacts recovered from specific archaeological layers show excellent agreement with the chronological record of the stratigraphically associated peat/gyttja (Figure 3).

The many dates measured at these two sites enabled us to compile a comprehensive history of the progressive development of each settlement throughout the past ten millennia (Figure 3). During their respective occupation spans both settlements were close to water bodies i.e. a lake or a river. This common topographical feature explains their multi-layered archaeological records that in turn reflect relatively frequent and discrete episodes of occupation by a sequence of ancient hunters and/ or fishermen. A finite time-span for each occupation layer in the archaeological reconstruction was defined by the ${ }^{14} \mathrm{C}$ ages obtained from a variety of sample types: peat/gyttja, wooden stakes, boards, elk bones (remnants of a food source), and fireplace charcoal. Similarities in the nature of the artifacts and their associated ages recorded at the two sites also allowed us to reconstruct patterns of human settlement and of co-existence of different cultures within the geographical area (Figure 3) and to highlight episodes of settlement interruption. Available evidence points to the influence of environmental change on human occupation; lake transgressions are marked by the deposition of gyttja or clay and river erosion events by sands in the peat strata. We were able to date these changes, either directly by dating peat and gyttja or indirectly by selecting organic materials above and below the sand and clay horizons. Consequently, we were able to set the environmental history of the Mezolithic and Neolithic inhabitants of Stanovoe-4 and Ivanovskoe-7 on a detailed ${ }^{14} \mathrm{C}$ time scale. 


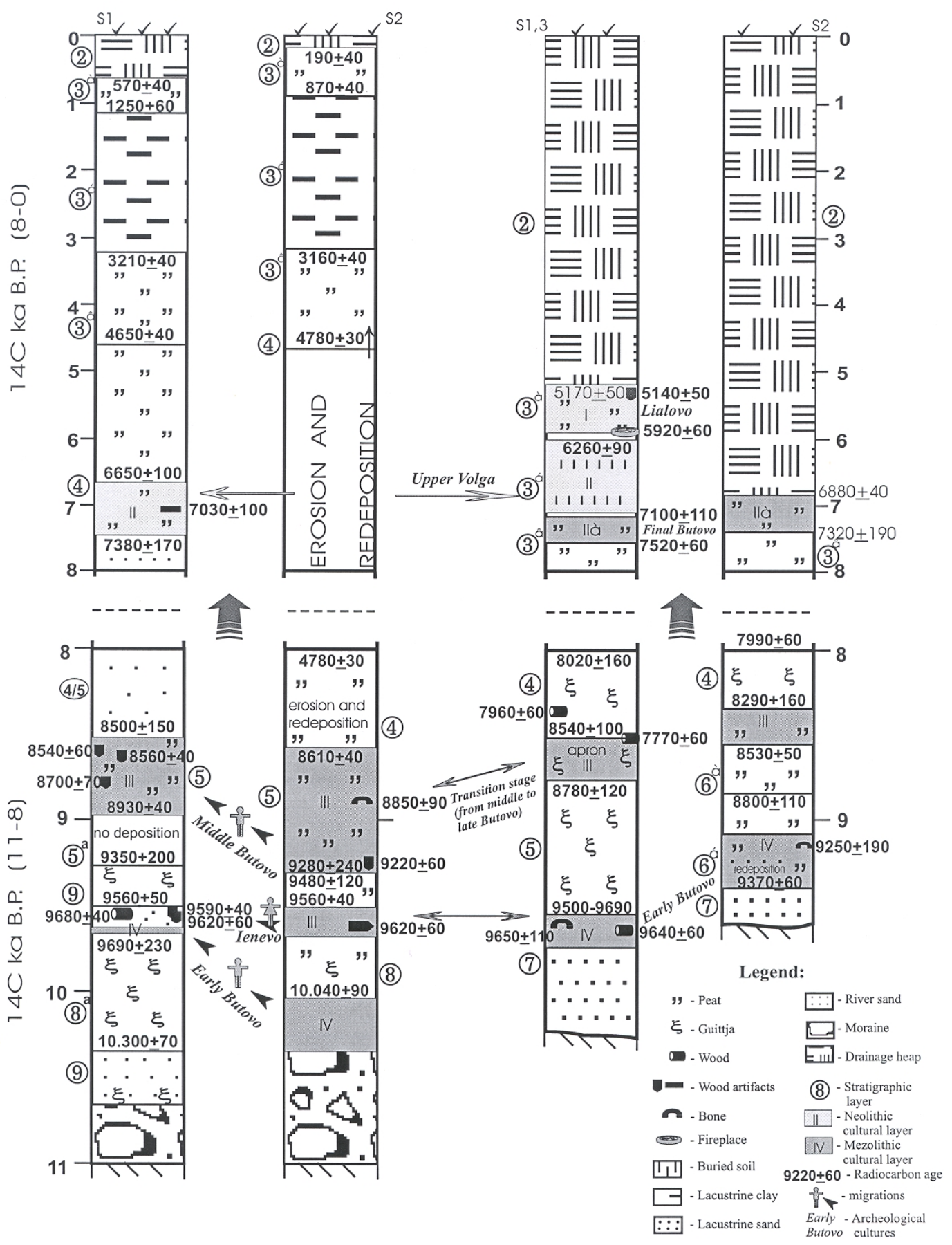

Figure 3 Settlement development history at Stanovoe-4 and Ivanovskoe-7 


\section{CONCLUSIONS}

It is our opinion that the concept of a "three-dimensional" approach in the dating of evidence recorded in peat bogs provides improved analytical confidence together with additional environmental and/or cultural information. This approach ensures an optimum scientific return in the application of ${ }^{14} \mathrm{C}$ dating to peat bogs and especially so in conjunction with other direct evidence, contained within the peat profiles, for events such as episodes of volcanic deposition and/or the cultural development of pre-historic populations.

This claim is well attested by the described case studies which have produced 1) a secure framework for the Holocene tephro-stratigraphy of South Kamchatka, and 2) a precise time scale for human activity at two discrete sites in the Upper Volga Basin.

The experimental program was successful in the resolution of various questions concerning the chronological integrity of peat as a dating source. Methods were developed and tested to ensure that the only the most appropriate materials were selected for dating and subsequent age interpretation.

Careful attention to the investigation and recording of ancillary information retained in the natural peat archives paid additional dividends for both environmental reconstruction and the sub-division of phases of cultural development. As evidenced from the Kamchatka project description, we have been able to establish the relationship between vegetation and volcanoes. At the Upper Volga sites the peat archive has been interpreted to provide a precise and detailed reconstruction of the paleoecological conditions within which pre-historic people lived.

We contend that a combination of the taphonomy and botanical origin of peat when allied with programs of careful and detailed ${ }^{14} \mathrm{C}$ age measurement is essential for the building of a reliable chronology for the evidence of various Holocene events that lies buried in peat bogs.

\section{ACKNOWLEDGMENTS}

This research was made possible thanks to field grant numbers 5926-97 and 6215-98 from the National Geographic Society and grants from the Russian Foundation for Basic Research.

\section{REFERENCES}

Braitseva OA, Melekestsev IV, Ponomareva VV, Sulerzhitsky LD. 1995. Ages of calderas, large explosive craters, and active volcanoes in the Kuril-Kamchatka region, Russia. Bulletin of Volcanology 57:383-402.

Braitseva OA, Melekestsev IV, Litasova SN, Sulerzhitsky LD, Ponomareva VV. 1993. Radiocarbon dating and teprochronology in Kamchatka. Radiocarbon 35(3): 463-77.

Khotinsky NA. 1977. Golocen Severnoi Evrazii (The Holocene of northern Eurasia). Moscow: Nauka. 198 p.

Pevzner MM, Ponomareva VV, Melekestsev IV. 1998. Chernyi Yar reference section of Holocene ash markers at the Northeastern coast of Kamchatka. Volcanology and Seismology 19(4):389-407.

Ponomareva VV, Dirksen OV, Sulerzhitsky LD. 1995. Eruptive history of Dikiy Greben volcano- the largest Holocene extrusive edifice in Kamchatka, Russia. Abstracts of the International Workshop on Volcanoes Commemorating the 50th Anniversary of Mt. Showa-
Shinzan. p 159.

Ponomareva VV, Sulerzhitsky LD, Dirksen OV, Zaretskaia NE. Holocene paleosols as records of the volcanic rest in the Kuril Lake region, South Kamchatka. Quaternaire. Forthcoming.

Stuiver M, Reimer PJ, Bard E, Beck JW, Burr GS, Hughen KA, Kromer B, McCormac FG, van der Plicht J, Spurk M. 1998a. Calibration Program rev. 4.2. Radiocarbon 40(3):1041-83.

Sulerzhitsky LD. 1997. Radiocarbon chronology of mammoths of Siberia and Norteastern Europe. Chelovek zaseliaet Zemliu. Globalnoe rasselenie gominid (The man inhabits the Earth. Global hominide settling). Moscow. p 184-200. In Russian.

Sulerzhitsky LD, Romanenko FA. 1999. The "twilight" of the mammoth fauna in the Asiatic Arctic. Ambio 28(3):251-55.

Sulerzhitsky LD, Zaretskaia NE, Zhilin MG. 1998. Radiouglerodnaia hronologia poselenia Ivanovskoe-7 (Ra- 
diocarbon chronology of Ivanovskoe-7 settlement). Nekotorie Itogy Izuchenia Ivanovskogo Bolota. Ivanovo. p 26-9. In Russian.

Zhilin M.G. 1998. Mnogosloinoe poselenie Ivanovskoe7 (Multilayer settlement Ivanovskoe-7). Nekotorie It ogy Izuchenia Ivanovskogo Bolota. Ivanovo. p 12-26.
In Russian.

Zhilin MG. 1999. The chronology and periodization of the Butovo Culture. In: Egorov PS, editor. The State History Museum-encyclopedia of the fatherland. Moscow. p 263-73. In Russian. 